\title{
HANDLING AND STABILITY ANALYSIS OF VEHICLES TOWING A TRAILER WITH NO BRAKES OR SUSPENSION
}

\author{
Luke Steiginga $^{1,2}$, Wei Huang ${ }^{1}$, Mark Croken ${ }^{1}$ \\ ${ }^{1}$ Automotive and Surface Transportation, National Research Council Canada, Ottawa, Canada \\ 2Luke.steiginga@nrc-cnrc.gc.ca
}

\begin{abstract}
The presence of suspension and brakes on a trailer can be important to safe handling when it is being towed by another vehicle. In most jurisdictions, there are limits specifying permissible gross weights for trailers without brakes. In Canada, waivers can be obtained for towing heavier trailers without brakes under certain conditions. In this study, NRC evaluated the performance characteristics of three vehicles towing a trailer with no brakes or suspension that had a mass of just over $5000 \mathrm{lbs}$., which is significantly greater than the typical provincial $3000 \mathrm{lbs}$. limit for trailers without brakes. The commercially available multibody dynamics software package TruckSim was used to build models for simulating standard manoeuvres to determine key performance measures for the tow vehicle and trailer combinations. The standard manoeuvres included a high-speed turn, a low-speed turn, a high-speed lane change, hard braking, and low-speed drives over bumps on straight and curved roads. Performance measures, which included various off-tracking values, static roll threshold, load transfer ratio, friction demand, lateral friction utilization, rearward amplification and rear outswing, were calculated for manoeuvres performed on a combination of low and high friction surfaces. Full scale physical testing of one tow vehicle and trailer combination was undertaken for the purpose of model tuning and validation. The analysis of the results from the validated models consisted of comparing the performance measures for each vehicle towing the trailer against known standards and against each other. It was determined that braking distance limits specified by FMVSS and CMVSS were met for the two larger vehicles when towing the trailer, but not for the smallest vehicle. Adding a brake package to the trailer would be recommended when towed by the smallest vehicle. It was also determined that the lack of suspension makes the trailer susceptible to roll instabilities when driven over uneven surfaces, regardless of the towing vehicle.
\end{abstract}

Keywords-simulation; multibody dynamics; truck; trailer; combinations; TruckSim; modelling; vehicle dynamics; validation

\section{INTRODUCTION}

Trailers are widely used on Canadian roads and most roads worldwide, and there is a great variety in the types of trailers and the vehicles that tow them. Although most trailers are equipped with suspension and braking systems, certain trailers are not. In general, but depending on province/country it is required that trailers with a mass of approximately $3000 \mathrm{lbs}$. or more be equipped with an independent braking system [1]. However, this study investigated a trailer with a mass above $5000 \mathrm{lbs}$. that is allowed to be towed in Canada for certain applications, with the appropriate waivers. This trailer also has no suspension.

The purpose of this study was to assess the ability of three different vehicles to safely tow this particular trailer. An 8 tonne truck and a 2.5 tonne truck, both of which have been used to tow the trailer in the past with a speed limit of $70 \mathrm{~km} / \mathrm{h}$ were considered in this work. A dual rear wheel pickup ("dually") was also considered.

In order to evaluate the performance of the vehicles towing the trailer, a model of each was built using the commercially available multibody dynamics software package TruckSim. TruckSim has been used by researchers for many applications involving heavy vehicle dynamic analyses [2]. In order to validate the dynamic models, physical testing was conducted with one of the trucks and the trailer, on a dedicated test track where measurements were made while performing a variety of maneuvers. The TruckSim model was then tuned such that there was good agreement between the simulated and measured results. One example of this is the suspension characteristics. The compression of the suspension systems on the truck were measured in the physical testing, and values were selected in the TruckSim model to approximately match these measurements. In the case of the front suspension, this resulted in a $600 \mathrm{~N} / \mathrm{mm}$ spring constant and a $50 \mathrm{kN} \cdot \mathrm{s} / \mathrm{m}$ damping coefficient. Additionally, it was verified that several larger scale performance characteristics such as the off-tracking and rearward amplification in the tested maneuvers were approximately matched with the simulation results. The validated truck and trailer combination models were then run through a series of standard maneuvers. By analyzing the results of these simulations, certain performance measures were calculated and were compared to known performance standards. 
This was done in a similar method as reported in previous studies such as [3].

\section{SIMULATIONS}

\section{A. Data and Limitations}

Detailed and accurate vehicle parameters are required to build high quality multibody dynamics models. For this work, the vehicle mass, center of mass, suspension type, tire size, drivetrain characteristics, and dimensional data were obtained from published data summary sheets and through physical measurements. As such, there is a large amount of confidence in this data. However, there was other information that was not readily available and required estimation. This included moments of inertia, some tire characteristics, suspension spring constants and damping coefficients, ABS braking systems specifications and the electronic stability control systems. . Some data gaps were addressed by scaling values from other similar vehicles. In the case of the braking system, a simple ABS model was used which would apply the brakes or release them based on the amount of slip between the tire and road. Additionally, the vehicles were modelled without any electronic stability control system.

\section{B. Validation and Tuning of the Model}

Based on the published data for the vehicles and the trailer and based on the estimations made by NRC, multibody dynamics models were built in TruckSim. However, it was important to validate the model and to make sure that the estimated values were reasonable. Therefore, full scale track testing with the large truck and trailer was conducted to validate and tune the models. The truck and trailer were instrumented with a variety of sensors to measure parameters such as speed, GPS location of the truck and trailer, suspension displacements, and relative motion between the truck and the trailer. The physical testing did not necessarily follow any standard maneuvers, but the maneuvers were done in such a way that they could be replicated in the simulations. Some maneuvers included low-speed turns, high speed turns, drives over bumps, lane changes, and stopping in a curve and while going straight. Based on the outputs of the simulation model, the suspension and tire characteristics were adjusted to match the test data. It was also verified that off-tracking, and rearward amplification values obtained between measurements and simulations were in acceptable agreement.

\section{Maneuvers and Performance Measures}

There have been many studies done in the past to evaluate the performance of truck and trailer combinations [4]. Based on these past studies, a list of standard maneuvers was created and used for this this study. The first maneuver was a low-speed turn in which the truck and trailer navigated a sharp turn at a speed of $8.25 \mathrm{~km} / \mathrm{h}$. The radius of the turn was $12.8 \mathrm{~m}$ at the front axle center [5]. For this maneuver, there were several performance measures. The first is the rear outswing, which is a measure of the maximum distance that the outer rear corner of the trailer sticks out from the path of the outside front wheel during the turn. The second performance measure for this maneuver is the front outswing. This is a measure of the extent to which the outer front corner of the truck deviates from the path of the outer front wheel during the turn. The third is known as the low-speed offtracking. This is a measure of the maximum distance between the path of the front inner wheel and the trailer's inner wheel during the turn. In other words, it is a measure the extent to which the trailer cuts the corner. This maneuver is often conducted on both high and low friction surfaces [5], and each of the performance measures listed were measured on both surfaces. However, there are two more performance measures for this maneuver that are only done on either the high or low friction surface. The first of these is the friction demand, which is the non-tractive friction on the tires that is required by the drive axles to successfully navigate the turn. This is measured on the drive axles of the truck by dividing the resultant shear force on the drive tires by the cosine of the articulation angle between the truck and trailer, and then dividing this value by the vertical load on these tires [5]. This performance measure is typically measured on high friction surfaces. The last performance measure for this maneuver was the lateral friction utilization, which is typically measured on low friction surfaces with a coefficient of friction of 0.2 . It is a measure of the amount of lateral friction utilization at the steering axle, and is calculated by dividing the sum of the lateral forces on the steer axle tires by the vertical load on these tires and by the coefficient of friction [5].

The second maneuver was a high-speed turn. This maneuver is typically done at a high coefficient of friction and all of the standard performance measures are measured on a high friction surface as well. This maneuver involves having the truck and trailer combination navigate a curve at high-speed with a curve radius that results in a lateral acceleration of approximately 0.2 $\mathrm{g}$ [4]. This radius is also dependent on the speed, but the speed was set to be $70 \mathrm{~km} / \mathrm{h}$ in this scenario as this is the operating speed limit for this particular truck and trailer combination. The first performance measure for this maneuver is the high-speed off-tracking which is a measure of the distance between the path of the center of the truck's front axle and the path of the center of the trailer's axle. The second performance measure for this maneuver is the static roll threshold. Similar to the previous performance measure, the evaluation of this measure involved having the truck and trailer combination navigate a high-speed curve with a speed and curve radius such that the lateral acceleration is $0.2 \mathrm{~g}$. Again, a speed of $70 \mathrm{~km} / \mathrm{h}$ was used with an appropriate radius; however, once steady state had been reached, the curve radius was steadily decreased so that the lateral acceleration increase [4]. The lateral acceleration at which one of the axles is fully unloaded on the inner side in this maneuver is known as the static roll threshold.

A lane change was the third maneuver assessed and is also typically done on a high coefficient of friction surface [6]. Again, the requirement for this standard is that the lane change yield a lateral acceleration amplitude of $0.15 \mathrm{~g}$ [6]. For this reason, the path of the vehicle was dictated such that the truck would have at least this value of lateral acceleration during the maneuver when the speed was $70 \mathrm{~km} / \mathrm{h}$. The first performance measure for this maneuver is the transient high-speed offtracking, which, similar to the high-speed off-tracking, is the maximum distance between the path of the front axle center and the path of the trailer axle center. The second performance 
measure is the rearward amplification. This is the ratio between the peak lateral acceleration of the center of mass on the trailer and the peak lateral acceleration of the center of mass on the truck. The last performance measure for this maneuver is the load transfer ratio, which provides an indication of how close the truck and trailer combination is to rolling over. It is a measure of the portion of the original load that shifts from the tire on one side of an axle to the tire on the other side of that axle. A load transfer ratio of 1 would mean that the tire on one side of the axle is bearing all the load and rollover could occur.

Hard braking maneuvers were also assessed. This was done on both a high and low friction surface. On the low-friction surface, the truck was run with an initial speed of $40 \mathrm{~km} / \mathrm{h}$ on a straight track that had a downhill grade of $5 \%$ with a coefficient of friction of 0.2 . The performance standard calculated for this maneuver is the braking distance, which is the distance the truck travels from the time the brakes are applied until it comes to a stop. This performance measure was also calculated on a straight and flat high friction surface where the initial speed was 96.56 $\mathrm{km} / \mathrm{h}(60 \mathrm{mi} / \mathrm{h})$ in order to be compared with known FMVSS standards [7]. Additionally, the braking distance was calculated when the truck was descending a hill with a coefficient of friction of 0.8 , a grade of $-20 \%$ and a curve radius of $152.4 \mathrm{~m}$ $(500 \mathrm{ft}$.), with an initial velocity of $70 \mathrm{~km} / \mathrm{h}$. For this case, the high-speed off-tracking value was also calculated.

In addition to these standard maneuvers, NRC also simulated some additional cases. The first of these involved a 6 in half round. The truck was run with a speed of $10 \mathrm{~km} / \mathrm{h}$ straight over the half round. The trailer would bounce off the ground and the roll angle was measured to provide an indication of the stability of the trailer. This maneuver was also repeated several times with different tire pressures as it was determined that the trailer roll angle was quite dependent on the estimated tire pressures. The truck and trailer combination were also run over the half round while navigating a corner at low-speed. In this case, the trailer roll angle was calculated, as well as the low-speed offtracking, rear outswing, and front outswing.

The last maneuver that was simulated, was a high-speed turn with a radius of $55 \mathrm{~m}$ and a speed of $60 \mathrm{~km} / \mathrm{h}$ on a surface with a coefficient of friction 0.8 . This maneuver was also conducted during the track testing. However, for this maneuver, a surface roughness was introduced to account for the fact that some roads may not be smooth. With a random surface roughness applied that had a maximum amplitude of about $30 \mathrm{~mm}$, the truck and trailer combination were run in a simulation on this same highspeed turn. The trailer roll angle was the main performance measure that was recorded and analyzed from this maneuver.

\section{RESULTS}

All of the performance measures were calculated from the simulation results. The relevant performance measures for each maneuver are shown in the tables below. Results for the rear outswing are not reported because no part of the trailer swung out past the positions of the front outer wheels on the trucks for any of the simulated maneuvers. This was mainly due to the relatively narrow shape of the trailer.

\section{A. Low-Speed Turn}

The low-speed turn was simulated first on a high friction surface with a coefficient of friction of 0.8 . In order to measure the low-speed off-tracking, front outswing, and rear outswing values, position sensors were added to the simulation model so that the paths of the key points needed to measure these performance characteristics could be plotted and the difference between the paths could be calculated. Table 1 shows all of the relevant results for this maneuver.

TABLE 1 RESUlts FOR LOW-SPEED TURN ON A High-Friction SURface

\begin{tabular}{|l|c|c|c|}
\hline $\begin{array}{c}\text { Performance } \\
\text { Measure }\end{array}$ & LSOT (m) & $\begin{array}{c}\text { Front } \\
\text { Outswing (m) }\end{array}$ & FD \\
\hline 8 Tonne Truck & 2.08 & 0.65 & 0.042 \\
\hline 2.5 Tonne Truck & 1.05 & 0.45 & 0.039 \\
\hline $\begin{array}{l}\text { Dually Pickup } \\
\text { Truck }\end{array}$ & 0.96 & 0.19 & 0.051 \\
\hline
\end{tabular}

Table 2 shows the results for the low-speed turn on a low-friction surface with a coefficient of friction of 0.2 . In this case, the lateral friction utilization was measured instead of the friction demand since this is a more relevant measure on a low friction surface.

TABLE 2 Results For LOW-SPEED TuRn On A LOW-Friciton SuRFACE

\begin{tabular}{|l|c|c|c|}
\hline $\begin{array}{c}\text { Performance } \\
\text { Measure }\end{array}$ & LSOT (m) & $\begin{array}{c}\text { Front } \\
\text { Outswing (m) }\end{array}$ & LFU \\
\hline 8 Tonne Truck & 1.56 & 0.63 & 0.76 \\
\hline 2.5 Tonne Truck & 0.90 & 0.42 & 0.64 \\
\hline $\begin{array}{l}\text { Dually Pickup } \\
\text { Truck }\end{array}$ & 0.97 & 0.35 & 0.35 \\
\hline
\end{tabular}

\section{B. High-Speed Turn}

The results for the high-speed turn are shown in Table 3. Note that there are two values shown for the static roll threshold. The first is the lateral acceleration at which one of the axles will be fully unloaded on one side and the second, referred to as the full static roll threshold (FSRT) in the table, is the lateral acceleration at which the entire vehicle is unloaded on one side and begins to roll. For the 8 tonne truck, the first axle to be fully unloaded on one side was the first axle on the truck. On the 2.5 tonne truck, the first axle to experience this was on the third axle of the truck. Additionally, for both of these trucks, the truck rolled over before the trailer. However, in the case of the dually pickup truck, the trailer axle was the one that rolled first, which also resulted in the entire trailer rolling over.

TABle 3 Results For High-SpEed Turn ON A High-Friction Surface

\begin{tabular}{|l|c|c|c|}
\hline $\begin{array}{c}\text { Performance } \\
\text { Measure }\end{array}$ & HSOT (m) & SRT (g) & FSRT (g) \\
\hline 8 Tonne Truck & 0.047 & 0.58 & 0.67 \\
\hline 2.5 Tonne Truck & 0.110 & 0.48 & 0.55 \\
\hline $\begin{array}{l}\text { Dually Pickup } \\
\text { Truck }\end{array}$ & 0.080 & 0.86 & 0.86 \\
\hline
\end{tabular}




\section{High-Speed Lane Change}

The results for the lane change maneuver are shown in Table 4. In this table, only the peak LTR for the truck is presented. For the 8 tonne, 2.5 tonne, and dually pickup trucks, the axles where this occurred were Axle 1, Axle 3, and Axle 2 respectively. Additionally, the only case where the LTR was higher on the trailer axle than on all the other axles was for the dually pickup truck. However, this was mostly due to the fact that this truck had a lower LTR than the others and not because the trailer LTR was much higher than it was when it was being towed by the other trucks.

TABle 4 Results For High-Speed Lane Change ON A High-Friction SURFACE

\begin{tabular}{|l|c|c|c|c|}
\hline $\begin{array}{l}\text { Performance } \\
\text { Measure }\end{array}$ & $\begin{array}{c}\text { THSOT } \\
(\mathbf{m m})\end{array}$ & RA & $\begin{array}{c}\text { Truck } \\
\text { LTR } \\
\text { (peak) }\end{array}$ & $\begin{array}{c}\text { Trailer } \\
\text { LTR }\end{array}$ \\
\hline 8 Tonne Truck & 28 & 1.23 & 0.41 & 0.35 \\
\hline $\begin{array}{l}2.5 \text { Tonne } \\
\text { Truck }\end{array}$ & 74 & 1.23 & 0.51 & 0.35 \\
\hline $\begin{array}{l}\text { Dually Pickup } \\
\text { Truck }\end{array}$ & 80 & 1.21 & 0.26 & 0.38 \\
\hline
\end{tabular}

\section{Hard Braking}

The results for the braking cases are shown in Table 5. Here it is clear that the Dually pickup truck has a braking distance that is between $29 \%$ and $89 \%$ greater than the 8 tonne truck. Also, the 2.5 tonne truck behaves in a manner that is quite similar to the 8 tonne truck for the first two braking cases, but when braking down a curve, it had a braking distance that was $70 \%$ higher. However, the HSOT values are quite similar in all of the cases.

TABLE 5 RESUlTS FOR HARD BRAKING TESTS

\begin{tabular}{|l|c|c|c|c|}
\hline \multirow{2}{*}{$\begin{array}{c}\text { Performance } \\
\text { Measure }\end{array}$} & $\begin{array}{c}\text { Straight } \\
\text { Braking } \\
(\boldsymbol{\mu}=\mathbf{0 . 8})\end{array}$ & $\begin{array}{c}\text { Downhill } \\
\text { Braking } \\
(\boldsymbol{\mu}=\mathbf{0 . 2})\end{array}$ & $\begin{array}{c}\text { Braking } \\
\text { Down a } \\
\text { Curve } \\
(\boldsymbol{\mu}=\mathbf{0 . 8})\end{array}$ & $\begin{array}{c}\text { HSOT } \\
(\mathbf{c m})\end{array}$ \\
\hline 8 Tonne Truck & 62.9 & 85.8 & 58.4 & 31 \\
\hline $\begin{array}{l}\text { 2.5 Tonne } \\
\text { Truck }\end{array}$ & 66.8 & 88.3 & 99.3 & 44 \\
\hline $\begin{array}{l}\text { Dually Pickup } \\
\text { Truck }\end{array}$ & 81.1 & 145.5 & 110.6 & 32 \\
\hline
\end{tabular}

\section{E. Half Rounds}

The most important performance measure for the maneuvers involving the half rounds was the roll angle of the trailer. In all of the cases, there was a relatively small amount of roll on the truck when compared with the roll on the trailer. Table 6 shows the roll angles for each of the tests.
TABle 6 Results For Roll ANGLEs On HALF Rounds

\begin{tabular}{|c|c|c|c|}
\hline \multirow[b]{2}{*}{$\begin{array}{c}\text { Performance } \\
\text { Measure }\end{array}$} & \multicolumn{3}{|c|}{ Roll Angle of Trailer (deg) } \\
\hline & $\begin{array}{c}\text { Straight Road } \\
(\mu=0.8)\end{array}$ & $\begin{array}{c}12.8 m \text { Radius } \\
\text { Road }(\mu=0.8)\end{array}$ & $\begin{array}{l}12.8 m \text { Radius } \\
\text { Road }(\mu=0.2)\end{array}$ \\
\hline 8 Tonne Truck & 13.8 & 8.8 & 17.6 \\
\hline $\begin{array}{l}2.5 \text { Tonne } \\
\text { Truck }\end{array}$ & 6.2 & 8.2 & 15.3 \\
\hline $\begin{array}{l}\text { Dually Pickup } \\
\text { Truck }\end{array}$ & 7.5 & 7.3 & 15.4 \\
\hline
\end{tabular}

The results shown in Table 6 were generated from simulation models in which the vertical tire stiffness was $980 \mathrm{~N} / \mathrm{mm}$. However, the assumed vertical tire stiffness, which is closely related to the tire pressure, was chosen somewhat arbitrarily. It was only based on some tires that appeared to be similar in the TruckSim library, and the roll angle result was shown to be quite sensitive to the vertical tire stiffness. Fig. 1 shows the roll angles for the different values of tire stiffness used when driving straight over the bump and demonstrates the sensitivity to tire pressure.

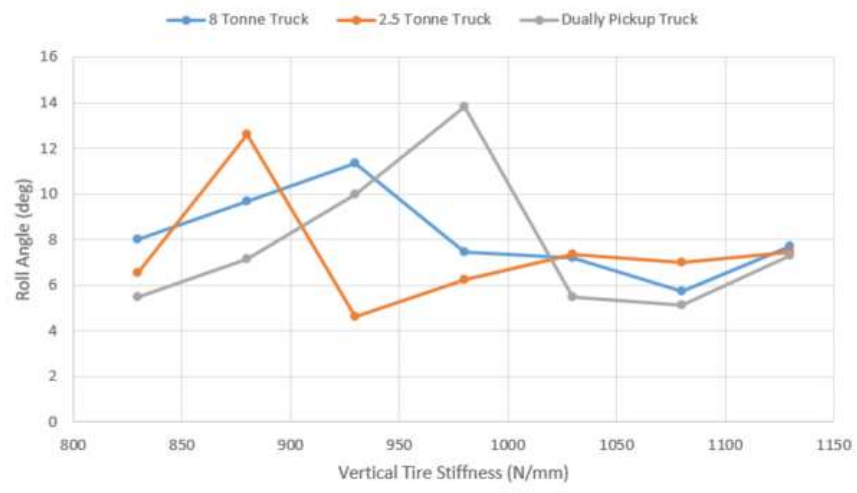

Figure 1. Roll Angle of Trailer at Different Tire Pressures when Driving Straight over 6 in. Half Round

\section{F. High-Speed Turn on Rough Surface}

During the physical testing, it was observed that the trailer would start to bounce when going around a turn at high speed. However, this was not the case in the simulations. This was important because the bouncing also caused some roll of the trailer. The likely reason for the presence of this bouncing and roll angle in the physical test and not in the simulated test is that the simulated test had a perfectly flat surface, whereas there would have been some surface roughness and minor road perturbations on the test track. Since the stability of the trailer while taking a turn is important on both flat and rough surfaces, an additional simulation was done with some surface roughness introduced. Fig. 2 shows the roll angle of the trailer during a high-speed turn with a $55 \mathrm{~m}$ radius done at a speed of $60 \mathrm{~km} / \mathrm{h}$ with a random surface roughness that had an amplitude of about $30 \mathrm{~mm}$. From the plot, it is clear that the trailer eventually starts to roll back and forth and that this problem worsens as the turn continues until the trailer completely rolls over. The rollover occurs regardless of which vehicle is used to tow the trailer. 


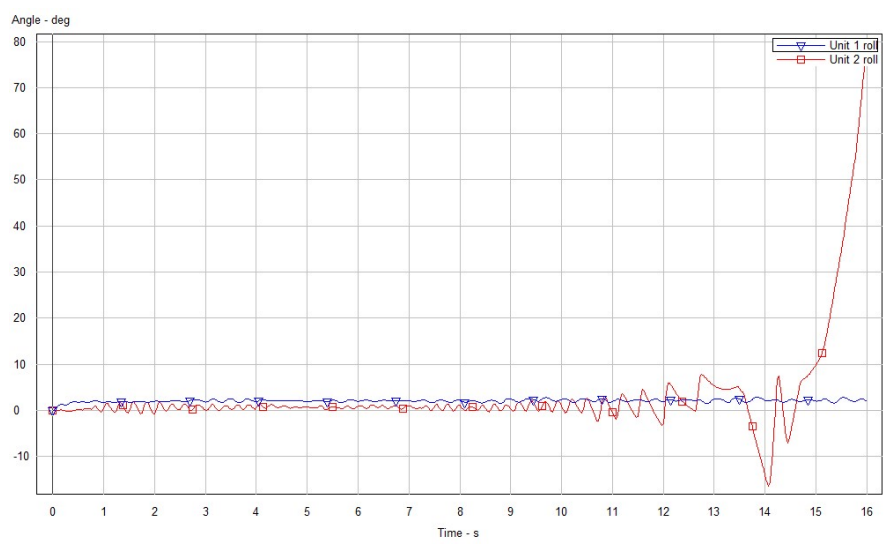

Figure 2. Roll Angle of Truck and Trailer during High-Speed Turn with Surface Roughness

\section{ANALYSIS AND DISCUSSION OF RESULTS}

Many of the performance measures shown in the results section can be compared to known performance standards. In this section, these will be compared. Additionally, the performance measures for the different vehicles will be compared with each other.

\section{A. Low-Speed Turn}

From the results of the low-speed turn, it can be seen that the 8 tonne truck had the greatest value of low-speed off-tracking, and the dually pickup truck had the lowest. This was an expected result since the larger vehicles have a greater distance between their drive axles and the trailer axles. However, all of the values for LSOT, whether on a high or low friction surface, were well below the performance standard of $6.0 \mathrm{~m}$ [6], which means that this is not much of a concern for any of the truck and trailer combinations.

The front outswing values were also greater on the larger vehicles, with the 8 tonne vehicle having the largest front outswing. However, due to the type of vehicle, it is generally acceptable for them to have a high value for the front outswing. The values were significantly higher than the performance standard, but this was not much of a concern for this particular vehicle. Additionally, all of the front outswing values recorded in this report were likely over-estimated due to the fact that no values were available from the vehicle data sheets nor were measured with precision instruments.

The rear outswing values were all seen to be zero due to the unique shape of the trailer. The trailer was quite thin at the rear end and therefore did not protrude during a turn. Therefore, this performance measure was not really relevant in this study.

The friction demand was shown to be greatest on the dually pickup truck, and lowest on the 2.5 tonne truck. However, even the dually pickup truck had a value that was $49 \%$ lower than the performance standard of 0.1 [5]. All of the lateral friction utilization values were also below the limit. In this case, the 8 tonne truck had the largest value, but it was still 5\% less than the performance standard of 0.80 [5].

Based on the results for the low-speed turn and the comparisons to the performance standards, all of the vehicles appear to be capable of towing the trailer safely. Additionally, no one vehicle outperforms the others for every performance measure.

\section{B. High-Speed Turn}

All of the performance measures for the high-speed turn met the performance standards. For the high-speed off-tracking, the 8 tonne truck performed the best, which was $57 \%$ lower than the worst and highest value that was obtained by the 2.5 tonne truck. However, even the 2.5 tonne truck had a value that was $76 \%$ lower than the limit of $0.46 \mathrm{~m}$ set by the performance standard [6].

All of the vehicles also met the limit set by the performance standard for the static roll threshold. This is particularly important since a rollover is a particularly dangerous situation. The performance standard specifies that the lateral acceleration required for the vehicle to rollover should be at least $0.40 \mathrm{~g}$ [6]. The 2.5 tonne truck came closest to this limit, but was still $20 \%$ higher than this value. This is expected since the vehicles themselves are all allowed to be used on the road; it is the trailer that is more of interest in this study. Since the vehicle rolled first when the maneuver was done on both of the heavier vehicles, the static roll threshold for the trailer can only be seen on the simulation for the dually pickup truck, where it was seen to be $115 \%$ higher than the performance standard.

\section{High-Speed Lane Change}

The first performance standard for this maneuver was the transient high-speed off-tracking. By this measure, the 8 tonne truck performed the best, but even the dually pickup truck with the highest value met and exceeded the performance standard of $0.8 \mathrm{~m}$ [6] by having a value that was only $10 \%$ of this limit.

All of the vehicles performed approximately the same in terms of the rearward amplification. They were all well below the limit set by the performance standard, which is 1.6 [6]. The values were about $23 \%$ less than the limit.

The last performance standard for this maneuver was the load transfer ratio. Based on the results, it is clear that the trailer performs about the same regardless of what is towing it. The value was slightly worse when the trailer was being towed by the dually pickup truck, but the value was still $37 \%$ lower than the limit value of 0.60 [6]. The load transfer ratios on individual axles on the trucks were actually higher. Again, the vehicles themselves were not the main focus of the study, but it is still important that they be able to meet the performance standards while towing the trailer. The 2.5 tonne truck had the highest value, but was still $15 \%$ lower than the limit value.

Similar to the previous maneuvers, it can be seen that all of the vehicles meet the performance standards for this maneuver. Also, no one vehicle performs significantly worse than the others for all of the performance measures. However, the 2.5 tonne truck is close to the limit for the load transfer ratio.

\section{Hard Braking}

For the hard braking down a curve, the high-speed offtracking values were acceptable. Even though the HSOT was not specifically intended for evaluating a hard braking maneuver, it 
is nonetheless a pertinent finding that the values were still less than the $0.46 \mathrm{~m}$ limit [6] for all the vehicles.

There is a significant difference in the braking distances for the different vehicles towing the trailer. The 8 tonne truck has the lowest braking distances for each braking maneuver, and therefore had the best performance. For the straight braking on a high friction surface and the downhill braking on a low friction surface cases, the 2.5 tonne truck did almost as well as the 8 tonne truck, with a slightly longer braking distance. Additionally, the braking distance on the straight, high-friction surface was found to be less than the maximum stopping distance of $76.2 \mathrm{~m}$ specified by CMVSS for this maneuver [7]. In fact, the heavier vehicles require approximately $10 \mathrm{~m}$ less braking distance than allowed by the standard. However, the 2.5 tonne truck does not perform as well as the 8 tonne truck when braking while descending the curve. In this case the braking distance was $70 \%$ larger than it was for the 8 tonne truck. This difference in even greater for the dually pickup truck. In this case, the braking distance was $89 \%$ larger than for the 8 tonne truck. Furthermore, the dually pickup truck does not perform nearly as well as the heavier trucks when performing the straight and downhill braking maneuvers. For the downhill braking on a low friction surface, the braking distance was $70 \%$ longer for the dually pickup truck compared to the 8 tonne truck. Additionally, the straight stop on the high-friction surface yielded a braking distance that was about $5 \mathrm{~m}$ higher than the maximum stopping distance of $76.2 \mathrm{~m}$ specified by CMVSS [7].

The increased braking distance for the dually pickup truck is likely due to the fact that the trailer has a significant weight when compared with this vehicle, whereas it's weight is less significant when compared to the heavier vehicles. Since the trailer is not equipped with brakes, the brakes on the truck must do all of the work. Based on the calculated braking distances, it can be concluded that the braking system on the dually pickup truck is incapable of providing sufficient braking when towing a 5000 lbs. trailer.

\section{E. Half Rounds}

There is no particular performance standard to use when evaluating the performance for this maneuver. However, from the results, it is clear that significant roll angles can occur on the trailer when it goes over a bump. This is likely due to the lack of suspension on the trailer. Although the trailer does not roll over during this maneuver, it is a concern that the roll angles reach values greater than 10 degrees.

\section{F. High-Speed Turn on Rough Surface}

As was described in the results section, all of the trailers experience rollover during a high-speed turn on a rough surface. Due to the lack of suspension, the trailer roll angle starts to increase as the maneuver is performed and increases as time progresses. This is a cause for concern if the truck and trailer combinations are to be used on non-level roads. For example, potholes, frequently found on Canadian roads, could easily cause surface variations of $3 \mathrm{~cm}$ or more, and this level of surface irregularity caused the trailer to rollover in the simulations.

\section{SUMMARY AND CONCLUSIONS}

Each of the truck and trailer combinations were able to perform the majority of the maneuvers while meeting the limits set by the various performance standards. This included a lowspeed turn, a high-speed turn and a high-speed lane change. However, there were issues associated with braking and uneven surfaces. It was shown that the 8 tonne truck performed the best in regards to braking distance. The 2.5 tonne truck was also able to meet the performance standard for braking, but yielded a significantly higher braking distance when braking downhill on a curve. The dually pickup truck performed worse in all of the braking tests and did not meet the performance standard.

Each of the truck and trailer combinations were also shown to be quite unstable on uneven surfaces. When towed over a 6 inch half round, the trailer experienced roll angles in excess of 10 degrees, for some tire pressure levels. This occurred regardless of which vehicle was towing the trailer. Additionally, the trailer was shown to be prone to rollover when going around a turn at high speeds on an uneven surface.

The lack of stability on uneven surfaces could be greatly improved by adding a suspension system to the trailer as was evidenced by the fact that the trucks, which had suspension, did not have roll angles that were nearly as high. Furthermore, the braking distance on all of the trucks could be improved by adding a braking system to the trailer. This is particularly important for towing with the dually pickup truck, as this vehicle/trailer combination did not meet the performance standard for braking.

\section{REFERENCES}

[1] AAA, "Digest of Motor Laws," 141 2020. [Online]. Available: https://drivinglaws.aaa.com/tag/trailer-brakes/.

[2] J. Deng, "Adaptation of a Trucksim Model To Experimental Heavy Truck Hard Braking Data," Ohio State University, Ohio, 2009.

[3] D. Pape, et.al., "Vehicle Stability and Dynamics Longer Combination Vehicles Final Report," National Transportation Research Center, Knoxville, 2011.

[4] J. R. Billing, "Evaluation of the Dynamic Performance of TruckRecreational Trailer Combinations," Trucking Policy Saskatchewan Highways and Transportation, Regina, 2007.

[5] S. Parker, "Investigation of Longer Modular Concept Configuration for British Columbia," International Forum for Road Transport Technology, Roturua, 2016.

[6] R. D. Ervin and Y. Guy, "The Influence of Weights and Dimensions of the Stability and Control of Heavy Trucks in Canada," Roads and Transportation Association of Canada, Ottawa, 1986.

[7] National Highway Traffic Safety Administration, Federal Motor Vehicle Safety Standards; Air Brake Systems, Washington: Department of Transportation, 2009. 